\title{
Aggressive incidents in psychiatric hospitals on heat days
}

\author{
Frank Eisele, Erich Flammer, Tilman Steinert and Hans Knoblauch
}

This study explores the relationship between temperature and the number of aggressive incidents and coercive interventions in the years 2007-2019 in six psychiatric hospitals in the south of the Germany with a total of 1007 beds. The number of aggressive incidents among 164435 admissions was significantly higher on 'heat days' $\left(\geq 30^{\circ} \mathrm{C}\right)$. Furthermore, there was a dose-response relationship between the number of aggressive incidents and increasing temperature. In contrast, the number of coercive interventions was not related to temperature. Considering the background of global warming, rising temperature could result in more frequent aggressive behaviour during in-patient treatment of psychiatric patients.

\section{Keywords}

In-patient treatment; aggression; coercion; temperature; heat days.

\section{Copyright and usage}

(C) The Author(s), 2021. Published by Cambridge University Press on behalf of the Royal College of Psychiatrists. This is an Open Access article, distributed under the terms of the Creative Commons Attribution-NonCommercial-NoDerivatives licence (http://creativecommons.org/licenses/by-nc-nd/4.0/), which permits non-commercial re-use, distribution, and reproduction in any medium, provided the original work is unaltered and is properly cited. The written permission of Cambridge University Press must be obtained for commercial re-use or in order to create a derivative work
Global warming is considered to be the greatest challenge for the 21st century. The mean global temperature is expected to rise between 2.6 and $4.8^{\circ} \mathrm{C}$ until the end of the century, depending upon varying climate scenarios. ${ }^{1}$ In Southern Germany the number of 'heat days' is estimated to double until $2050 .^{2}$ Elevated temperature has been associated with aggressive behaviour. ${ }^{3}$ There is increasing evidence that elevated temperature is also associated with a variety of psychiatric conditions, for example increased suicide rates and higher number of psychiatric hospital admissions. ${ }^{4}$

About $17 \%$ of admitted psychiatric patients engage in violent behaviour, leading to containment measures by staff, such as seclusion, restraint and involuntary medication. ${ }^{5,6}$ However, to our knowledge, there are no data available on the relationship between temperature and aggressive behaviour of individuals with psychiatric disorders during treatment in psychiatric hospitals. It could be anticipated that global warming will reinforce these conditions because of a greater number of heat days and might therefore impose additional challenges on psychiatric hospitals in the future.

\section{Method}

The study sites were six psychiatric hospitals in the south of the German Federal State of Baden-Wuerttemberg (Centers for Psychiatry Suedwuerttemberg) with a total of 1007 beds. All six hospitals provide good and modern building standards. However, air conditioning was not regarded as necessary and is not available.

Violent incidents were recorded with the Staff Observation Aggression Scale - Revised (SOAS-R), completed by staff members after each incident with five items: provocation; means used by the patient; target of aggression; consequences for victims; and measures to stop aggression. ${ }^{7}$ Data on coercive interventions such as seclusion and restraint, as well as the SOAS-R, were extracted from the electronic patient information system, which was identical for all participating hospitals. ${ }^{8}$ We counted the number of recorded aggressive incidents and measures of seclusion or restraint, independent of their duration. In accordance with the
University of Ulm as well as national legislation and institutional requirements ethical approval was not required for retrospective studies analysing anonymised data.

Temperature data were obtained from the German Weather Service (https://www.dwd.de/DE/Home/home_node.html). As no measurement of weather data was undertaken at the precise site of the hospitals, the Weather Service determined a total of ten measurement stations next to the respective sites and we assigned the measurements to the hospital sites. The distance between weather stations and hospitals was between 20 and $30 \mathrm{~km}$. The temperature used for the analysis was the highest daily temperature. Since the temperature inside the building is likely to be more constant, the outside temperature was assumed as a rough approximation for average inside temperature.

First, we determined the total number of 'heat days', defined by international agreement by an average temperature of $\geq 30^{\circ} \mathrm{C}\left(86^{\circ} \mathrm{F}\right)$, at all measurement stations. We considered different options but finally decided that one measurement $>30^{\circ} \mathrm{C}$ at any weather station defines a heat day for the whole area. We decided on this option, because days with a temperature $\geq 30^{\circ} \mathrm{C}$ were quite rare and the differences between weather stations were small. Metric temperature data was available only for days with $\geq 30^{\circ} \mathrm{C}$. We did not try to obtain other data because lower temperatures measured outside correlate probably only to all small extent with temperatures inside buildings due to insolation and heating. However, as air conditioning is not available in the hospital buildings, outside temperatures over about $25^{\circ} \mathrm{C}$ correlate well with temperatures inside the buildings. Therefore, we decided to restrict our analyses to heat days and summarised all non-heat days $\left(<30^{\circ} \mathrm{C}\right)$ into one category.

We then determined the number of aggressive incidents and coercive measures on heat days and on all other days and calculated the respective ratio per day for days $<30^{\circ} \mathrm{C}$ and $\geq 30^{\circ} \mathrm{C}$. Significant differences were determined using Student's $t$-test.

To test for a dose-response relationship, we further subdivided the data-set into temperature categories including one category for all days with a temperature $<30^{\circ} \mathrm{C}$. Significance was determined using analysis of variance (ANOVA). The statistical significance of linear trends was determined by planned linear polynomial contrasts. 
Table 1 Aggressive incidents and coercive interventions with respect to temperature

Temperature Days Aggressive incidents Aggressive incidents/days Coercive interventions Coercive interventions/days

Non-heat versus heat days

$>30^{\circ} \mathrm{C}, n$

$<30^{\circ} \mathrm{C}, n$

$207 \quad 2016$

t-test, $P$

$4541+38190$

38190

9.7

8.4

$<0.01$

Incremental temperature increases

$<30^{\circ} \mathrm{C}, n$

$>30.0$ to $<30.5^{\circ} \mathrm{C}^{\circ} \mathrm{C}, n$

$\geq 30.5$ to $<31.5^{\circ} \mathrm{C}, n$

$>31.5$ to $<32.5^{\circ} \mathrm{C}, n$

$>32.5$ to $<33.5^{\circ} \mathrm{C}, n$

$>33.5^{\circ} \mathrm{C}, n$

Total, $n$

ANOVA, $P$

Linear trend, $P$

$\begin{array}{rrrrr}4541 & 38190 & 8.4 & 70889 & 15.6 \\ 59 & 565 & 9.6 & 957 & 16.2 \\ 82 & 798 & 9.7 & 1352 & 16.5 \\ 33 & 297 & 9.0 & 499 & 15.1 \\ 18 & 189 & 10.5 & 293 & 16.3 \\ 15 & 167 & 11.1 & 239 & 15.6 \\ 4748 & 40206 & 8.5 & 74229 & 15.6 \\ & & <0.05 & & \text { n.s. }\end{array}$

\section{Results}

Over 4748 days ( 13 years), there were a total of 207 heat days $(4.36 \%$ of all days). Among 164435 admissions, 40206 violent incidents and 74229 coercive measures were recorded. We observed a significant difference in aggressive incidents on days with temperatures $<30^{\circ} \mathrm{C}$ and $\geq 30^{\circ} \mathrm{C}(P<0.01)$. There was a slight but insignificant difference in the use of coercive interventions (Table 1).

Furthermore, Table 1 shows the dose-response relationship between temperature categories and number of aggressive incidents. The cumulative number of aggressive incidents per temperature category increased from $8.4<30^{\circ} \mathrm{C}$ up to $11.1>33.5^{\circ} \mathrm{C}$ (ANOVA: $P<0.05$; linear trend: $P<0.01)$. There was no such relationship for the number of coercive interventions.

\section{Discussion}

To our knowledge, this is the first study providing evidence for an impact of elevated ambient temperature on aggressive behaviour in psychiatric in-patients. The assumption of a causal association is strengthened by evidence for a dose-dependent relationship. Against a background of worldwide climate change and increasing acknowledgement of environmental influences on the origin, and course of, mental disorders this finding could be relevant for further research and clinical practice as well. A relationship between aggressive behaviour and temperature is well-known from different perspectives, ${ }^{3}$ yet there has been no evidence in the field of mental disorders so far.

\section{General aggression model}

The nature of the relationship between temperature and aggression has long been debated. Some authors are in favour of a curvilinear model, whereas others are in favour of a U-shaped relationship. ${ }^{9}$ Our analysis showed a linear trend for the relationship between aggressive behaviour and temperature. The predominant model to explain this relationship is the general aggression model. ${ }^{10}$ This model hypothesises a variety of external inputs influencing decision-making processes concerning aggressive behaviour against a background of internal dispositions, for example emotional status or stress level. Ambient temperature would be considered one of these external factors. Based on the assumption that in response to aversive stimuli individuals choose either to fight or to flee (negative affect escape model ${ }^{11}$ ), this model predicts that the tendency to aggressive behaviour increases up to a certain degree until individuals will try to escape the situation to minimise individual discomfort, resulting in a reduction in aggressive behaviour. Although this possibility might be relevant for individuals in their daily environment, this escape is less likely to be possible in a psychiatric hospital setting, particularly for those involuntarily detained because of being a danger to others or self.

Interestingly, the dose-response relationship could not be demonstrated for coercive measures taken by staff. In our experience, a reason for this could be that in days with extremely high temperatures seclusion rooms have such a high temperature that staff are sometimes advised to avoid using these rooms because of considerations about patient safety and staff safety. Seclusion rooms are used for seclusion and mechanical restraint with 1:1 supervision.

\section{Limitations}

In this analysis we could not take into account any covariates, such as other climate-related variables or staffing levels, and data on the temperature within the buildings were not available. However, these factors probably have not caused systematic error and their interactions could be an objective of further research.

\section{Implications}

This study has some consequences for further research and practice. The next challenge for research will be to replicate these findings with multiple measurements inside of psychiatric wards. Consequences for hospital management and planning are under discussion already. An obvious consequence would be changes in the planning of buildings, by installing air conditioning in new buildings or retrofitting it in existing buildings. However, this strategy has some serious flaws: First, this kind of solution is part of the problem, if air conditioning is not use purely regenerative energy sources. Second, air conditioning means keeping windows and doors of terraces, patios and balconies closed, which would mean an end to our concept of open psychiatric wards. ${ }^{12}$ 'Open' in this sense means more than entrance doors that are not locked; patients may feel locked in if they cannot open a window in their room or the door to a secured balcony. Thus, our recommendations for architectural planning are rather to keep the heat outside using smart building techniques such as optimal use of insulation materials, sensor-driven shutters or heat exchange systems under floors. The future will show whether these approaches can cope with the challenge of increasing periods of high temperatures.

Frank Eisele, Centers for Psychiatry Suedwuerttemberg Germany; Erich Flammer Centers for Psychiatry Suedwuerttemberg, University of Ulm, Germany; Tilman Steinert, Centers for Psychiatry Suedwuerttemberg, University of UIm, Germany; Hans Knoblauch (D), Centers for Psychiatry Suedwuerttemberg, Germany

Correspondence: Hans Knoblauch. Email: hans.knoblauch@zfp-zentrum.de

First received 17 Nov 2020, final revision 1 Feb 2021, accepted 3 Mar 2021 


\section{Data availability}

Data that support the findings of this study are available on request from the corresponding author (H.K.).

\section{Author contributions}

All authors met ICMJE criteria for authorship. All authors were involved in critical discussion, revision and final approval of the work. F.E. and E.F. extracted and processed the necessary data and performed the statistical analysis. H.K. drafted the initial version of the manuscript. T.S. provided the temperature data and drafted the interpretation of the data.

\section{Funding}

This research received no specific grant from any funding agency, commercial or not-for-profit sectors.

\section{Declaration of interest}

None.

\section{References}

1 Stocker TF, Qin D, Plattner GK, Tignor M, Allen SK, Boschung J, et al, eds. Climate Change 2013: The Physical Science Basis. Contribution of Working Group I to the Fifth Assessment Report of the Intergovernmental Panel on Climate Change. Cambridge University Press, 2013.

2 LUBW State Institute for Environment, Measurements and Nature Conservation Baden-Württemberg. Monitoring-Bericht zum Klimaschutzgesetz BadenWürttemberg. [Monitoring report on the Baden-Württemberg Climate Protection Act.] Verlagspublikation Umweltverwaltung Baden-Württemberg, 2017 (https://www.lubw.baden-wuerttemberg.de/Klimawandel-und-anpassung/klimamonitoring).
3 Van Lange $\mathrm{P}$, Rinderu $\mathrm{M}$, Bushman $\mathrm{B}$. Aggression and violence around the world: a model of Climate, Aggression, and Self-control in Humans (CLASH). Behav Brain Sci 2017; 40: e75.

4 Obradovich N, Migliorini R, Paulus MP, Rahwan I. Empirical evidence of mental health risks posed by climate change. Proc Natl Acad Sci U S A 2018; 115: 10953-58.

5 Iozzino L, Ferrari C, Large M, Nielssen O, de Girolamo G. Prevalence and risk factors of violence by psychiatric acute inpatients: a systematic review and metaanalysis. PLOS One 2015; 10: e0128536.

6 Steinert $T$, Lepping $P$, Bernhardsgrütter R, Conca A, Hatling $T$, Janssen W. Incidence of seclusion and restraint in psychiatric hospitals: a literature review and survey of international trends. Soc Psychiatry Psychiatr Epidemio 2010; 45: 889-97.

7 Nijman HL, Palmstierna T, Almvik R, Stolker JJ. Fifteen years of research with the Staff Observation Aggression Scale: a review. Acta Psychiatr Scand 2005; 111 12-21.

8 Flammer E, Frank U, Steinert T. Restrictive coercive measures in forensic psychiatry. Front Psychiatry 2020; 11: 146

9 Anderson CA, Bushman BJ. Human aggression. Annu Rev Psychol 2002; 53 : 27-51.

10 Allen JJ, Anderson CA, Bushman BJ. The General Aggression Model. Curr Opin Psychol 2018; 19: 75-80.

11 Anderson CA. Temperature and aggression: ubiquitous effects of heat on occurrence of human violence. Psychol Bull 1989; 106: 74-96.

12 Steinert $T$, Schreiber L, Metzger FG, Hirsch S, Open doors in psychiatric hospitals: an overview of empirical findings. Nervenarzt 2019; 90: 680-9 [in German]. 